\title{
Wettability Behavior of XLPE Nanocomposite with Surface Modified Nanofiller
}

\author{
Anuaruddin Hanizan, Rahida Wati Sharudin, Zakiah Ahmad, Istikamah Subuki, Azerai Ali \\ Rahman
}

\begin{abstract}
Advanced polymer materials typically is used as an insulator in the electrical cable, especially in medium and high voltage applications. Cross-linked polyethylene (XLPE) is preferred due to its excellent insulation character despite its deficiency on the higher water absorption ability by the composite has exposed the material toward electrical treeing forming and shorten the lifetime of the material against electrical charges. The intention of this study is to observe the surface free energy and wetting behaviour of XLPE with the combination of surface modified nanosilica and nanoclay by using contact angle assessment with water and methylene iodide as the solvents. The analysis shows that the incorporation of organoclay with XLPE has a greater non-wetting behaviour up to 5 wt \% of nanoclay, as well as a decreasing pattern of the surface free energy by $36 \%$ compared to the neat XLPE system. Results of the study suggest that the improvement on the hydrophobicity of the nanocomposites is contributed by the microstructure development, in which the latter is also related to the dielectric response enhancement.
\end{abstract}

Keywords : Contact angle, Dielectric, Hydrophobicity, Wettability, XLPE.

\section{INTRODUCTION}

Polymer composites have become a popular choice in the electrical cable industries as the main material of insulation for decades. The main function of insulation is to resist the electric current flowing through the material, as well as protecting the user from the electrical leakage. Polymer not only possess a good mechanical strength, but it also has an excellent flexibility and high resistance to chemical reaction, which is important qualities for the insulation of electrical cable. However, continuous and increased use of electricity that is in line with development have a long-term impact on the durability of the insulator itself.

Engagement of nanofillers with XLPE has further exposed the enhancement of the properties of the mixture and reduced the incompatibility issue between matrix and inorganic fillers [1], [2]. Studies have shown that the incorporation of nanofillers, such as silica $\left(\mathrm{SiO}_{2}\right)$, zinc oxide $(\mathrm{ZnO})$, calcium

Revised Manuscript Received on November 19, 2019

Anuarudin Hanizan, Faculty of Chemical Engineering, Universiti Teknologi MARA, Shah Alam, Selangor, MALAYSIA. Email: anuaruddinhanizan@gmail.com

Rahida Wati Sharudin*, Faculty of Chemical Engineering, Universiti Teknologi MARA, Shah Alam, Selangor, MALAYSIA. Email: rahida@uitm.edu.my

Zakiah Ahmad, Faculty of Civil Engineering, Universiti Teknologi MARA, Shah Alam, Selangor, MALAYSIA. Email: zakiah@uitm.edu.my

Istikamah Subuki, Faculty of Chemical Engineering, Universiti Teknologi MARA, Shah Alam, Selangor, MALAYSIA. Email: istikamah@uitm.edu.my

Azerai Ali Rahman, Faculty of Civil Engineering, Universiti Teknologi MARA, Shah Alam, Selangor, MALAYSIA. Email: azerai@uitm.edu.my carbonate $\left(\mathrm{CaCO}_{3}\right)$, silicon carbide $(\mathrm{SiC})$, boron $(\mathrm{BN})$, titanium oxide $\left(\mathrm{TiO}_{2}\right)$, and aluminium oxide $\left(\mathrm{Al}_{2} \mathrm{O}_{3}\right)$ has the ability to modify the dielectric properties of polyethylene [1], [3]-[6] and improve the mechanical and thermal properties of the nanocomposites [2], [7], [8]. Study on the adoption of modified nanoparticles in nanocomposites blend was found to be able to assist in providing higher compatibility between polymer and nanofiller [9].

In recent times, contact angle is a notorious and uncomplicated character to represent the tendency of fluid to be spread on the solid surfaces. Contact angle helps researcher to analyse various elements on the surface of the composite, such as the hydrophilicity and hydrophobicity of the composite, roughness of surface, liquid surface tension, and the surface energy of the solid [10], [11]. It is a simple method of measurement, where the importance lies in how the liquid is used in determining wettability of the solid surface by observing the angle between the tangent of liquid-vapour surface and solid-liquid surfaces, as depicted in Fig. 1. Meanwhile, the surface tension is related to the amount of force needed for the molecules at surface to engage with one another to retain the structure of liquid.

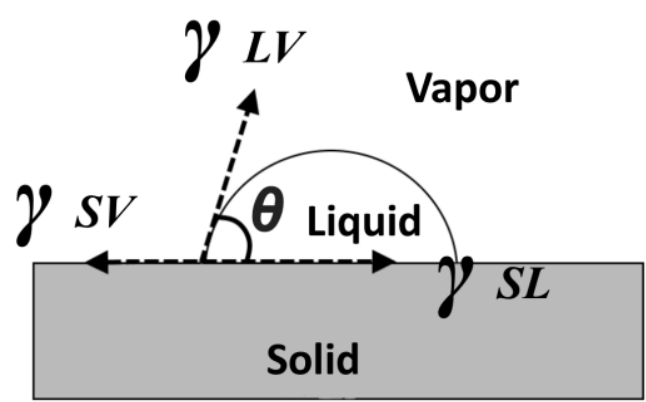

Fig. 1: Interpretation of surface tension on solid-liquid (SL), liquid-vapour (LV) and solid-vapour (SV) surfaces.

Wettability is well known as the degree of dispersion of fluid on the solid material surface. In context of XLPE nanocomposites, the water spreading rate on its surface would be used to determine the interfacial capabilities by viewing the contact angles between liquid and XLPE surface. Surface energy of liquid is important in measuring the wettability, as the extent of liquid spreading on the XLPE surfaces depends on the magnitude of solid surface energy. 


\section{Wettability Behavior of XLPE Nanocomposite with Surface Modified Nanofiller}

Higher surface energy compared to the surface tension is needed to spread the water on the surface of the polymer.

Lower wettability of polymer is favourable for dielectric material, especially for insulation application, so there will be minimal risk of water leaching effect, in which the water leaching effect could turn into water treeing initiation and growth, thus, leading to mechanical deterioration [12]. Application of nanofiller, especially for the electrical power industry, has shown a tremendous or significant advancement on the dielectric behaviour [13], [14]. Less wettability of the polymer materials increases the effectiveness of insulation material, as its opposing water ingress into the polymer nanocomposite network due to the hydrophobicity increment by the solid surfaces.

A study reported by Huang et al. [15] has shown that the implication of nanosilica in the linear low density polyethylene (LLDPE) composites has a vital progression on the dielectric permittivity, as well as water treeing growth suppression. Josmin et al. [16] asserted that the fusion of modified silica and clay had certainly improved the hydrophobicity of the XLPE matrix due to the contribution of interaction between the nanofiller and the XLPE composite in the interfacial region. Therefore, the focus of the present study is to understand the effect of nanofiller on the wettability of XLPE nanocomposites and at the same time, to reveal the optimum formulation that can help in improving the properties of the nanocomposites. This specific effect was linked to the dielectric properties of the nanocomposites, where the interfacial region of polymer matrix contributes to the dielectric enhancement.

\section{MATERIAL AND METHOD}

\section{A. Sample Preparation}

First, there are five types of raw materials involved in this study, which are low density polyethylene (LDPE), polyethylene with $0.1 \%$ maleic anhydride (PE-g-MAH), an antioxidant Irganox, a cross-linking agent dicumyl peroxide (DCP), and the organically modified clay, CLOISITE-10A that was obtained from Southern Clay Products, India.

Modified silica was prepared by dispersing silica in ethyl alcohol solution, with the addition of bis-(triethoxysilypropyl) disulfide (TESPD) as a coupling agent. Ultrasonic dispersion was used after 30 minutes of stirring process of the mixture. The mixture was then centrifuged. Finally, the modified silica particles were dried in a vacuum oven at $190^{\circ} \mathrm{C}$.

Nanocomposites are prepared by melt mixing technique using dicumyl peroxide as the curing agent. The nanocomposites with $0.5,1,2,2.5,5$, and $10 \mathrm{wt} \%$ nanoparticles are prepared. The PE-g-MAH 5 wt \%, cross-linking agent, DCP $1.5 \mathrm{wt} \%$ and antioxidant $0.5 \mathrm{wt} \%$ are used. The mixing process is carried out in a Hake mixer at $160^{\circ} \mathrm{C}$ at $60 \mathrm{rpm}$ for 12 minutes. The mixed nanocomposites are compression-moulded into a sample of 2 $\mathrm{mm}$ in thickness using a hydraulic press at $180^{\circ} \mathrm{C}$ for 5 minutes with the maximum pressure of $200 \mathrm{~kg} / \mathrm{cm}^{2}$. Composite of XLPE are also prepared as a references sample by the same method and ingredient as above, and without the addition of any nanocomposites.

\section{B. Contact Angle Measurement}

The specimens were cut into a rectangle shape, with a size of $1 \times 1 \times 0.2 \mathrm{~cm}^{3}$ for each of the formulation, including the neat samples. The testing was carried out using SEO Phoenix instrument with distilled water and methylene iodide (MI) were used as a solvent in this study. Higher attention in handling the sample is required, especially on the surface of the specimen to ensure low risk of contamination. The volume of water drop was standardised at $5 \mu \mathrm{L}$ per drop for all sessions and the measurement was done within $\sim 40-60 \mathrm{~s}$ after the water is dropped onto the surface of the specimen.

Table I: Sample used in the contact angle measurement.

\begin{tabular}{llc}
\hline Samples & \multicolumn{1}{c}{$\begin{array}{c}\text { Types of } \\
\text { Nanofiller }\end{array}$} & $\begin{array}{c}\text { Nanofiller Weight } \\
\text { Percentage, wt \% }\end{array}$ \\
\hline XLPE & - & - \\
Silica 1 & Silica & 0.5 \\
Silica 2 & Silica & 1.0 \\
Silica 3 & Silica & 2.0 \\
Silica 4 & Silica & 2.5 \\
Silica 5 & Silica & 5.0 \\
Silica 6 & Silica & 10.0 \\
Clay 1 & CLOISITE-10A & 0.5 \\
Clay 2 & CLOISITE-10A & 1.0 \\
Clay 3 & CLOISITE-10A & 2.0 \\
Clay 4 & CLOISITE-10A & 2.5 \\
Clay 5 & CLOISITE-10A & 5.0 \\
Clay 6 & CLOISITE-10A & 10.0
\end{tabular}

\section{Theory and Calculation of Contact Angle Measurement}

All of the equations mentioned in this section were used to calculate the parameter required in this study and these equations have been verified by previous studies [11], [16]-[18]. In many cases, a finite contact angle, $\theta$, will be created when a smooth solid surface is in contact with the liquid. As the liquid reaches the equilibrium, it will form two tangent planes between solid-liquid and liquid-vapour phases, as shown in Fig. 1. Young [19] has derived a basic equation that expresses the connection between solid, liquid and vapour in the Equation (1):

$\gamma_{S}=\gamma_{S L}+\gamma_{L} \cos \theta$

where, $\gamma_{S}$ and $\gamma_{L}$ are the surface free energy of solid and liquid, respectively, while $\gamma_{\mathrm{SL}}$ is the interfacial energy between liquid and solid. The contact angle between the solid and liquid region is referred as $\theta$. In term of wettability, technically, the pattern of liquid droplet is driven by the surface tension at the solid surface. Fig. 2 shows three conditions of the contact angle with different shapes of the liquid droplets.

When the contact angle is less than $90^{\circ}$, it indicates that the solid surface has a favourable wetting behaviour, while droplet with a contact angle of more than $90^{\circ}$ behave as nearly to a non-wetting property with minimal contact and spreading of liquid, as illustrated in Fig. 2(c). 
a) $\theta<90^{\circ}$

Good wetting

b) $\theta=90^{\circ}$

$\gamma s L=\gamma s V$

c) $\theta>90^{\circ}$

Non wetting

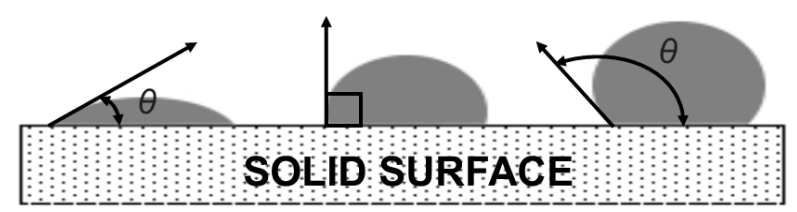

Fig. 2: Sketch of liquid drop with different contact angle.

Owen-Wendt's [20] theory propose that the polar attraction and solid dispersion forces are essential to represent the total surface energy of a solid due to the significance of both elements in influencing the interaction between the solid molecules. The equation is described as:

$$
\gamma_{S}=\gamma_{S}^{d}+\gamma_{S}^{p}
$$

where, $\gamma_{S}{ }^{\mathrm{d}}$ and $\gamma_{\mathrm{S}}{ }^{\mathrm{p}}$ represent the solid surface free energy for the dispersion component and polar component, respectively.

$\mathrm{Wu}$ [21], on the other hand, introduced another method in determining the interfacial energy between polymer-polymer or polymer-liquid interaction, based on the reciprocal mean equation. This method has been confirmed by a few studies, as he suggested to merge the polar and dispersion element into Equation (2) in order to set the $\gamma_{\mathrm{S}}$ value.

However, this approach is only applicable when used with at least two different testing liquids with different polarities. For the present study, water and methylene iodide were used to find the $\gamma_{S}$ of the XLPE nanocomposites, as both liquids have been recommended by other researchers [18], [21]-[25]. The equations for both liquids are expressed as below:

$\left(1+\cos \theta_{W}\right) \gamma_{W}=4\left[\frac{\gamma_{W}^{d} \gamma_{S}^{d}}{\gamma_{W}^{d}+\gamma_{S}^{d}}+\frac{\gamma_{W}^{p} \gamma_{S}^{p}}{\gamma_{W}^{p}+\gamma_{S}^{p}}\right]$

and,

$$
\left(1+\cos \theta_{M I}\right) \gamma_{M I}=4\left[\frac{\gamma_{M I}^{d} \gamma_{S}^{d}}{\gamma_{M I}^{d}+\gamma_{S}^{d}}+\frac{\gamma_{M I}^{p} \gamma_{S}^{p}}{\gamma_{M I}^{p}+\gamma_{S}^{p}}\right]
$$

where, $\gamma_{s}{ }^{d}$ and $\gamma_{s}{ }^{p}$ for each of the nanocomposite were worked out by mathematical solver software. All data for water and methylene iodide can be found in Table II.

The calculation for the work of adhesion was done by using Equation (5):

$$
W_{A}=(1+\cos \theta) \gamma_{L}
$$

In this case, the $\mathrm{W}_{\mathrm{A}}$ value is the interpretation of the amount of energy change needed to isolate the two different phases: liquid and nanocomposites surfaces.

For interfacial tension energy, the $\gamma_{\mathrm{SL}}$ and spreading coefficient, $S_{C}$ were calculated based on Equation (6):

$\gamma_{S L}=\gamma_{S}+\gamma_{L}-W_{A}$ and Equation (7):

$$
S_{C}=\gamma_{S}-\gamma_{S L}-\gamma_{L}
$$

where, the spreading coefficient indication was used to observe the tendency of water and methylene iodide to be dispersed on the surface of the sample.

In contemplation of conceiving the interaction between the nanocomposite surface and water/methylene iodide, the Girifalco-Good's interaction parameter, $\Phi$, was used, as shown below:

$\Phi=\frac{\gamma_{L}(1+\cos \theta)}{2\left(\gamma_{L} \gamma_{S}\right)^{1 / 2}}$

Table II: Data of surface energy of water and methylene iodide [21], [26].

\begin{tabular}{lccc} 
Liquid & $\begin{array}{c}\boldsymbol{\gamma}_{\mathbf{L}} \\
\left(\mathbf{m} \mathbf{J} / \mathbf{m}^{\mathbf{2}}\right)\end{array}$ & $\begin{array}{c}\boldsymbol{\gamma}_{\mathbf{L}}{ }^{\mathbf{d}} \\
\left(\mathbf{m} \mathbf{J} / \mathbf{m}^{\mathbf{2}}\right)\end{array}$ & $\begin{array}{c}\gamma_{\mathbf{L}}{ }^{\mathbf{p}} \\
\left(\mathbf{m} \mathbf{J} / \mathbf{m}^{\mathbf{2}}\right)\end{array}$ \\
\hline Water & 72.8 & 21.8 & 51.0 \\
Methylene Iodide & 50.8 & 49.5 & 1.5 \\
\hline
\end{tabular}

\section{RESULTS AND DISCUSSION}

The contact angle measurement of liquid droplet on the surface modified XLPE nanocomposites was conducted. All measurement and experiment were carried out in room condition. Contact angle value is essential for this study as all the parameters such as interfacial energy, work of adhesion, spreading coefficient value and Girifalco-Good's interaction parameter were derived from this data. Fig. 3 and Fig. 4 display the comparison of contact angle between the XLPE/nanosilica and XLPE/nanoclay with water and methylene iodide as solvent.

Based on the result shown in Fig. 3, the adoption of nanosilica as filler in the XLPE show a decrease in inclination, where both of the solvent measurements show a similar declining graph. This result reflects that the hydrophilicity of the polymer increases with the increase of the nanofiller loading, compared to the neat XLPE. The lowest contact angle reading was the Silica 4, where the contact angle recorded is $67^{\circ}$ and $43^{\circ}$ for water and methylene iodide solvent, respectively.

However, a different outcome was seen in the XLPE/nanoclay nanocomposites. The graph displays an increasing trend upon increment of CLOISITE-10A concentration for both solvents. The contact angles for neat XLPE of water solvent are $82^{\circ}$ and $99^{\circ}$ with methylene iodide. The surge of the contact angle in XLPE/nanoclay nanocomposites pointed out that the incorporation of nanoclay has raised the hydrophobicity of the XLPE. Poor wetting conditions were disclosed, as the polymer nanocomposites surfaces repelled the polar liquid water up to $5 \mathrm{wt} \%$ of formulation. At $10 \mathrm{wt} \%$ of CLOISITE-10A loading, the nanocomposites surfaces show a small downturn, and this is due to the higher compactness of nanofiller in the XLPE composite that affects the dispersion of nanofiller on the polymer matrix.

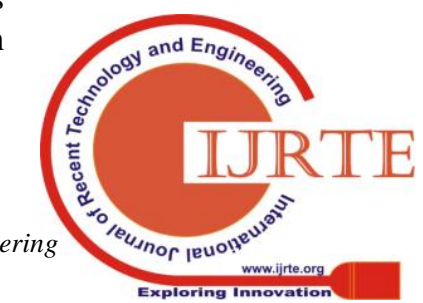




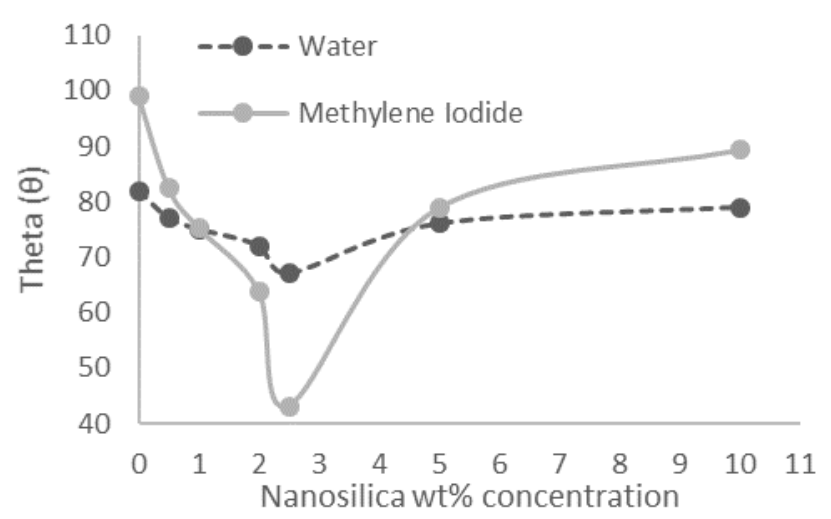

Fig. 3: Contact angle comparison for XLPE/nanosilica with water and methylene iodide as solvent.

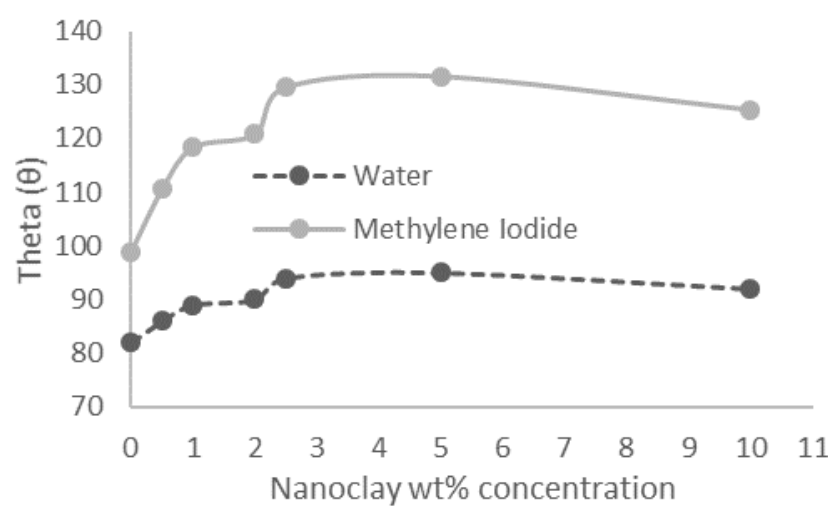

Fig. 4: Contact angle comparison for XLPE/nanoclay with water and methylene iodide as solvent.

Neat XLPE portrays a slight wetting behaviour with a contact angle less than $90^{\circ}$. Melt blending of CLOISITE-10A with XLPE has turned the nanocomposites into a non-wetting medium and it has been justified by the contact angle recorded. Basically, CLOISITE-10A is organically modified montmorillonite and the modifier is known as dimethyl, hydrogenated tallow, quarternary ammonium with concentration of $125 \mathrm{meq} / 100 \mathrm{~g}$. The used of surface modification is to improves the nanofiller distribution by lessen the interlayer attractive forces and overcome the filler agglomeration issues [27].

Work of adhesion generally refers to the energy needed to distinguish between the solvent dropped and the surface of the nanocomposites. The work of adhesion of XLPE/nanosilica and XLPE/nanoclay nanocomposites with water solvent as a function of filler loading were plotted in Fig. 5. $\mathrm{W}_{\mathrm{A}}$ of XLPE/nanosilica increases, while the XLPE/nanoclay show an upset trend with increment of the filler concentration. A gradual declining of $\mathrm{W}_{\mathrm{A}}$ demonstrates an excellent interaction between the polymer and the filler with positive filler distribution into polymer matrix, thus improving the hydrophobicity of the nanocomposites as well [18], [28].

Fundamentally, the spreading of liquid happens when the spreading coefficient is in positive value, while there will be no spreading if the value is in negative value. From the result shown in Table III and Table IV, it clearly shows that both types of nanocomposites displayed a non-wetting behaviour. However, in XLPE/nanoclay, the spreading coefficient became more negative compared to the neat XLPE. Thus, the data indicated that the XLPE/nanoclay possessed higher hydrophobicity upon loading filler, compared to the XLPE/nanosilica nanocomposites.

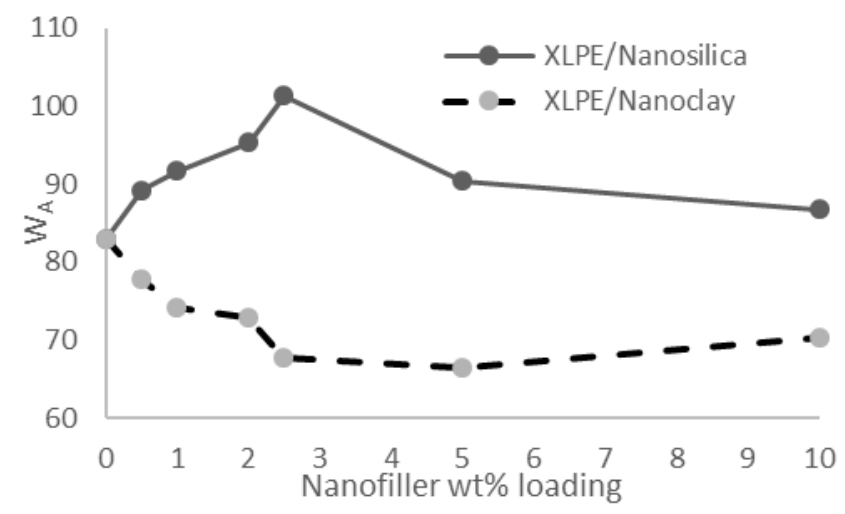

Fig. 5: $W_{A}$ of XLPE/nanosilica and XLPE/nanoclay against filler loading in water solvent.

Consequently, this study reported that the XLPE/nanoclay composites exhibits low interaction with both solvents compared to the neat polymer. Girifalco-Good's interaction parameter is used to understand the intermolecular forces acting across the interfaces of the solid and liquid [29]. The interaction is considered equal, if the intermolecular forces between the both solid and liquid is similar to each other. However, the rising of nanoclay filler loading in has caused a declining trend of interaction parameter in both solvents, especially in methylene iodide, which expressed the low interaction between the liquid surfaces and polymer surface. This shows that incorporating CLOISITE-10A into XLPE matrix as a filler is a practical method for helping in developing the hydrophobic character of the polymer composite and by altering the surfaces' hydrophobicity.

Nevertheless, nanosilica filler has increased the interaction of XLPE surfaces with the test liquid as the results show the interaction parameter value in methylene iodide increases from 0.56 in neat XLPE to the highest interaction value, 0.93 at $2.5 \mathrm{wt} \%$ of the nanosilica loading formulation. The water solvent also shows a decreasing trend, but only in a small value. Therefore, this result indicated that the nanosilica possessed high tendency of interaction with the liquid at the surfaces, thus increasing nanocomposites surfaces' hydrophilicity characteristics.

Surface free energy can be elucidated as surface tension of the solid. Theory proposed by Owen-Wendt [20] deduced that the surface free energy of a solid comprises intermolecular interaction, especially at the region between the solid and liquid, where the dispersion forces and polar forces are. Surface free energy of a solid helps in determining the sum of energy that required by a liquid to break the existing intermolecular interaction at the solid surfaces. Based on Fig. 6 , incorporation of nanosilica in the XLPE matrix display a rising trend with the increment of filler loading up to $2.5 \mathrm{wt} \%$ compared to the CLOISITE-10A effect on the XLPE matrix. The least surface free energy recorded for the XLPE/nanoclay is at $5 \mathrm{wt} \%$ of filler, with the value of $18.72 \mathrm{~mJ} / \mathrm{m}^{2}$. Whereas, the surface energy recorded for neat system is $29.16 \mathrm{~mJ} / \mathrm{m}^{2}$, where the percentage decreased by $36 \%$.

Published By: Blue Eyes Intelligence Engineering \& Sciences Publication 
Table III: Spreading coefficient $\left(\mathrm{S}_{\mathrm{C}}\right)$ and Girifalco-Good's interaction parameter $(\Phi)$ of XLPE/nanoclay.

\begin{tabular}{lcccc}
\hline Sample & $\begin{array}{c}\mathbf{S}_{\mathbf{C}} \\
\text { (Water) }\end{array}$ & $\begin{array}{c}\mathbf{S}_{\mathbf{C}} \\
(\mathbf{M I})\end{array}$ & $\begin{array}{c}\boldsymbol{\Phi} \\
\text { (Water) }\end{array}$ & $\begin{array}{c}\boldsymbol{\Phi} \\
(\mathbf{M I})\end{array}$ \\
\hline XLPE & -62.67 & -58.68 & 0.90 & 0.56 \\
Clay 1 & -67.72 & -68.62 & 0.90 & 0.46 \\
Clay 2 & -71.53 & -74.90 & 0.90 & 0.39 \\
Clay 3 & -72.80 & -76.76 & 0.90 & 0.37 \\
Clay 4 & -77.88 & -83.16 & 0.90 & 0.29 \\
Clay 5 & -79.14 & -84.50 & 0.90 & 0.28 \\
Clay 6 & -75.34 & -80.17 & 0.90 & 0.33 \\
\hline
\end{tabular}

Table IV: Spreading coefficient $\left(\mathrm{S}_{\mathrm{C}}\right)$ and Girifalco-Good's interaction parameter ( $\Phi)$ of XLPE/nanosilica.

\begin{tabular}{lcccc}
\hline Sample & $\begin{array}{c}\mathbf{S}_{\mathbf{C}} \\
\text { (Water) }\end{array}$ & $\begin{array}{c}\mathbf{S}_{\mathbf{C}} \\
(\mathbf{M I})\end{array}$ & $\begin{array}{c}\boldsymbol{\Phi} \\
\text { (Water) }\end{array}$ & $\begin{array}{c}\boldsymbol{\Phi} \\
(\mathbf{M I})\end{array}$ \\
\hline XLPE & -62.67 & -58.68 & 0.90 & 0.56 \\
Silica 1 & -56.42 & -44.08 & 0.90 & 0.69 \\
Silica2 & -53.96 & -37.82 & 0.90 & 0.75 \\
Silica 3 & -50.30 & -28.35 & 0.90 & 0.83 \\
Silica 4 & -44.35 & -13.74 & 0.90 & 0.93 \\
Silica 5 & -55.19 & -40.97 & 0.90 & 0.72 \\
Silica 6 & -58.91 & -50.15 & 0.90 & 0.64 \\
\hline
\end{tabular}

The low value of surface free energy corresponds to the low wettability of the material surface. Therefore, as a result, the CLOISITE-10A is the most suitable nanoparticles to shrink the surface area of the liquid and reduce the surface free energy on the XLPE surfaces, as it helps in promoting hydrophobic characteristic of the XLPE.

The CLOISITE-10A improves the hydrophobicity of the XLPE nanocomposites by providing a better dispersion between organoclay and the matrix. The maleic anhydride compatibiliser used during polymerisation of the nanocomposites has provided a significant effect on the intermolecular strength of the XLPE/nanoclay. This is due to the hydrogen bonds creates by the compliment of hydroxyl groups from the CLOISITE-10A silicates layers with the carbonyl groups of the maleic anhydride. The schematic diagram of reaction is depicted in Fig. 7, and the similar finding was found by Kannan et. al [9] upon study on the nanoclay filled polyurethanes and polypropylene blends. An extremely good dispersion of higher loading CLOISITE-10A in the XLPE nanocomposite caused a rise of density in the structure of the nanocomposite, thus enhancing the water-repellent characteristic. The existence of hydrogen bond at the interfacial region of CLOISITE-10A and XLPE matrix is potentially able to increase the dielectric properties of the material, as this bonding could help in forming the trap side for the electron and suppress the charge mobility throughout the nanocomposites structure, as depicted in Fig. 7. The study on adoption of organically modified clay with various types of polymers has proven to intensify the dielectric behaviour towards the insulation application [30]-[33].

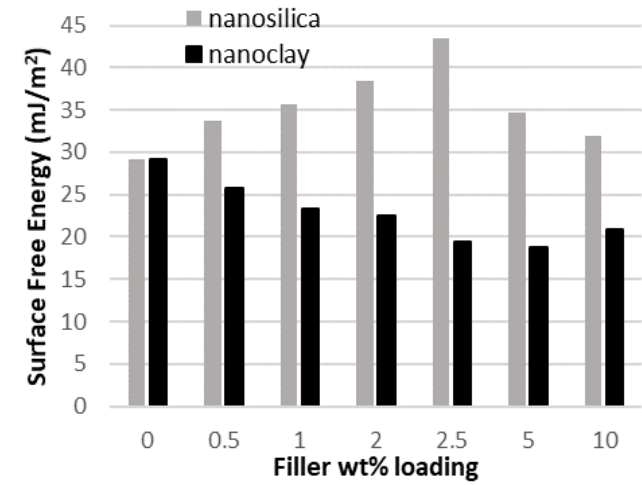

Fig. 6: Comparison of surface free energy for XLPE/nanosilica and XLPE/nanoclay against the percentage of filler content.

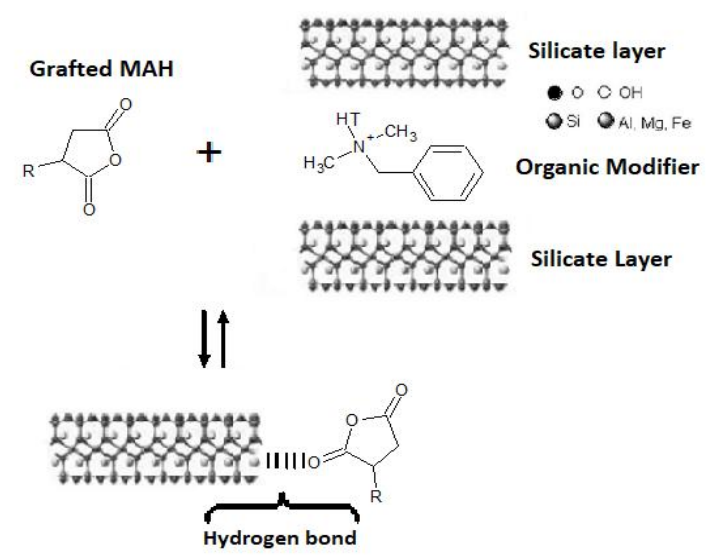

Fig. 7: Schematic of hydrogen bonding between hydroxyl group from CLOISITE-10A with anhydride.

As discussed earlier in the Introduction section, high water absorption is one of the causes of breakdown for the insulation polymer in the electrical cable, especially underground and subsea applications. The absorption of water by the polymer is mainly influenced by the hydrophilicity nature of the polymer itself. The combination of electrical stress and humidity factor could initiate the water treeing effect and the water ingress into the polymer matrix, making it worse, sooner or later [12], [34]. Therefore, having a hydrophobic material as an insulation is crucial to scale down the risk of water ingress into the polymer in the event of high electrical stress, which could initiate the breakdown of the insulation material itself.

\section{CONCLUSION}

In conclusion, the effect of nanofiller on the wettability of XLPE nanocomposites has been successfully observed. From the observations, it was found that the addition of CLOISITE-10A into the XLPE matrix has reduced the contact angle between the test liquid and the nanocomposites surfaces. 5 wt $\%$ of the CLOISITE-10A is the optimum concentration for the filler to achieve a better wettability property for an insulation application, such as having high contact angle, low surface free energy, negative value of spreading coefficient, and exhibiting low interaction with the liquid.

Published By:

Blue Eyes Intelligence Engineering \& Sciences Publication 


\section{Wettability Behavior of XLPE Nanocomposite with Surface Modified Nanofiller}

All the results indicated that the XLPE/nanoclay possessed a hydrophobic character in contrast to the neat XLPE and XLPE/nanosilica composites. This character is essential in improving the dielectric properties of the XLPE, as the hydrogen bonding created at the interfacial region of nanocomposites can aid in boosting the hydrophobicity of the polymer and serve as a charge trap at the same time.

\section{ACKNOWLEDGMENT}

This research is funded under the Geran Insentif Penyeliaan: 600-IRMI 5/3/GIP (048/2018) by the Ministry of Education Malaysia given to the Faculty of Chemical Engineering of Universiti Teknologi MARA (UiTM) Selangor.

\section{REFERENCES}

1. J. P. Jose, Z. Ahmad, and S. Thomas, "Hybrid Nanoparticle-Based XLPE / SiO 2 / TiO 2 and XLPE / SiO 2 Nanocomposites : Nanoscale Hybrid Assembling , Mechanics and Thermal properties," in Proceedings of the International Civil and Infrastructure Engineering Conference 2013, Sarawak, Malaysia, 2013, pp. 895-902.

2. J. P. Jose and S. Thomas, "12 Cross-linked Polyethylene Nanocomposites for Dielectric Applications," Adv. Compos. Mater. Prop. Appl., pp. 527-544, 2017.

3. J. Yang, X. Wang, C. Zheng, H. Zhao, and Q. Lei, "DC conduction properties of SiO/LDPE nanocomposite," in 2012 IEEE 10th International Conference on the Properties and Applications of Dielectric Materials, Bangalore, India, 2012, pp. 1-4.

4. N. S. Mansor et al., "Influence of $\mathrm{ZnO}$ and $\mathrm{Al} 2 \mathrm{O} 3$ nanofillers on electrical treeing in XLPE insulation," in 2017 International Conference on High Voltage Engineering and Power Systems, Bali, Indonesia, 2017, pp. 327-330.

5. J. Xiang, S. Wang, P. Chen, and J. Li, "Space Charge Characteristics in XLPE / BN Nanocomposites at Different Temperatures," in 2018 12th International Conference on the Properties and Applications of Dielectric Materials (ICPADM), Xi'an, China, 2018, pp. 952-955.

6. C. Zhang, R. Mason, and G. Stevens, "Preparation, Characterization and Dielectric Properties of Epoxy and Polyethylene Nanocomposites,' IEEJ Trans. Fundam. Mater., vol. 126, no. 11, pp. 1105-1111, 2006.

7. J. P. Jose and S. Thomas, "Alumina-clay nanoscale hybrid filler assembling in cross-linked polyethylene based nanocomposites: Mechanics and thermal properties," Phys. Chem. Chem. Phys., vol. 16 , no. 28, pp. 14730-14740, 2014.

8. Y. Wang, C. Wang, and K. Xiao, "Investigation of the electrical properties of XLPE/SiC nanocomposites," Polym. Test., vol. 50, pp. 145-151, 2016.

9. M. Kannan, S.S. Bhagawan, Tomlal Jose, Sabu Thomas, Kuruvilla Joseph, "Preparation and Characterization of Nanoclay-Filled Polyurethane/Polypropylene Blends," Polym. Eng. Sci., vol. 50, no. 9, pp. $1878-1886,2010$.

10. A. Marmur, "Equilibrium and Spreading of Liquids on Solid Surfaces," Adv. Colloid Interface Sci., vol. 19, pp. 75-102, 1983.

11. D. O. Njobuenwu, E. O. Oboho, and R. H. Gumus, "Determination of Contact Angle from Contact Area of Liquid Droplet Spreading on Solid Substrate," Leonardo Electron. J. Pract. Technol., vol. 6, no. 10, pp. 29-38, 2007.

12. F. Mauseth and M. Amundsen, "Water Tree Growth of Wet XLPE Cables Stressed with DC and High Frequency AC Voltage Superimposed," in 2012 IEEE International Symposium on Electrical Insulation, San Juan, Puerto Rico, 2012, pp. 266-269.

13. V. Tomer, G. Polizos, C. A. Randall, and E. Manias, "Polyethylene nanocomposite dielectrics: Implications of nanofiller orientation on high field properties and energy storage," J. Appl. Phys., vol. 109, no. 7, pp. 1-11, 2011.

14. D. Ma et al., "Influence of nanoparticle surface modification on the electrical behaviour of polyethylene nanocomposites," Nanotechnology, vol. 16, no. 6, pp. 724-731, 2005.

15. X. Huang, F. Liu, and P. Jiang, "Effect of Nanoparticle Surface Treatment on Morphology, Electrical and Water Treeing Behavior of LLDPE Composites," IEEE Trans. Dielectr. Electr. Insul., vol. 17, no. 6, pp. 1697-1704, 2010.

16. J. P. Jose, J. Abraham, H. J. Maria, K. T. Varughese, and S. Thomas,
"Contact Angle Studies in XLPE Hybrid Nanocomposites with Inorganic Nanofillers,” Macromol. Symp., vol. 366, no. 1, pp. 66-78, 2016.

17. F. Hejda, P. Sola`, and J. Kousal, "Surface Free Energy Determination by Contact Angle Measurements - A Comparison of Various Approaches," in WDS' 10 Proceedings of Contributed Papers, Prague, Czech Republic, 2010, no. 3, pp. 25-30.

18. S. P. Thomas, S. Thomas, R. Abraham, and S. Bandyopadhyay, "Polystyrene / calcium phosphate nanocomposites: Contact angle studies based on water and methylene iodide," eXPRESS Polym. Lett. vol. 2, no. 7, pp. 528-538, 2008.

19. T. Young, "III. An Essay on the Cohesion of Fluids," Philos. Trans. R. Soc. London, vol. 95, pp. 65-87, 1805.

20. R. C. W. D. K. Owens, "Estimation of the Surface Free Energy of Polymers," Appl. Polym., vol. 13, no. 8, pp. 1741-1747, 1969.

21. S. Wu, "Calculation of Interfacial Tension in Polymer Systems," J. Polym. Sci. Part C Polym. Symp., vol. 34, no. 1, pp. 19-30, 1971.

22. Y. C. Ko, B. D. Ratner, and A. S. Hoffman, "Characterization of Hydrophilic-Hydrophobic Polymeric Surfaces by Contact Angle Measurements," J. Colloid Interface Sci., vol. 82, no. 1, pp. 25-37, 1981.

23. J. W. Lin, L. E. S. P. Dudek, and D. Majumdar, "Wetting Properties of Homopolymers and Copolymers of Pentafluorostyrene and Methylacrylate and Homopolymer Blends," J. Appl. Polym. Sci., vol. 33, no. 2, pp. 657-667, 1987.

24. A. El-Shimi, E.D. Goddard, "Wettability of Some low Energy Surfaces I . Air / Liquid / Solid Interface," J. Colloid Interface Sci., vol. 48, no. 2, pp. 242-248, 1974.

25. R.A Pyter, G. Zografi, P. Mukerjee, "Wetting of Solids by Surface-Active Agents: The Effects of Unequal Adsorption to Vapor-Liquid and Solid-Liquid Interfaces," J. Colloid Interface Sci., vol. 89, no. 1, pp. 144-153, 1982.

26. F. Comte and D. Sage, "Contact angles of water (polar) and methylene iodide (non polar) on glass surfaces treated with aminosilane/ mercaptosilane mixtures. Correlation between silane orientation, surface tensions and wetting hysteresis," Macromol. Symp., vol. 23, no. 1, pp. 299-305, 1989.

27. A. Tcherbi-Narteh, M. V. Hosur, E. Triggs, and S. Jelaani, "Effects of Surface Treatments of Montmorillonite Nanoclay on Cure Behavior of Diglycidyl Ether of Bisphenol A Epoxy Resin,” J. Nanosci., vol. 2013, pp. 1-12, 2013.

28. J. P. Jose, J. Abraham, H. J. Maria, K. T. Varughese, and S. Thomas, "Contact Angle Studies in XLPE Hybrid Nanocomposites with Inorganic Nanofillers," Macromol. Symp., vol. 366, no. 1, pp. 66-78, 2016.

29. A. J. Jose and M. Alagar, "Preparation and characterization of polysulfone-based nanocomposites," in Manufacturing of Nanocomposites with Engineering Plastics, Elsevier Ltd., 2015, pp. 31-59.

30. G. Wu, Y. Cheng, K. Wang, and Y. Wang, "Fabrication and characterization of OMMt / BMI / CE composites with low dielectric properties and high thermal stability for electronic packaging," $J$ Mater. Sci. Mater. Electron., vol. 27, no. 6, pp. 5592-5599, 2016.

31. A. Jayakrishnan, D. Kavitha, A. Arthi, N. Nagarajan, and M. Balachandran, "ScienceDirect Simulation of electric field distribution in nanodielectrics based on XLPE," in Materials Today: Proceedings in Recent Advances In Nano Science And Technology 2015 (RAINSAT2015), Sathyabama University, India, 2016, vol. 3, no. 6, pp. 2381-2386.

32. T. Tanaka, "Enhanced Partial Discharge Resistance of Epoxy / Clay Nanocomposite Prepared by Newly Developed Organic Modification and Solubilization Methods," IEEE Trans. Dielectr. Electr. Insul., vol. 15 , no. 1, pp. 81-89, 2008.

33. X. Li, M. Xu, K. Zhang, D. Xie, and X. Cao, "Influence of Organic Intercalants on the Morphology and Dielectric Properties of XLPE / montmorillonite Nanocomposite Dielectrics," IEEE Trans. Dielectr. Electr. Insul., vol. 21, no. 4, pp. 1705-1717, 2014.

34. H.-H. S. and Frank Mauseth, Sverre Hviddsten and J. Aakervik, "Influence of DC Stress Superimposed with High Frequency AC on Water Tree Growth in XLPE Insulation," in Proceedings of the 23rd Nordic Insulation Symposium, Trondheim, Norway, 2013, pp. 53-56. 


\section{AUTHORS PROFILE}

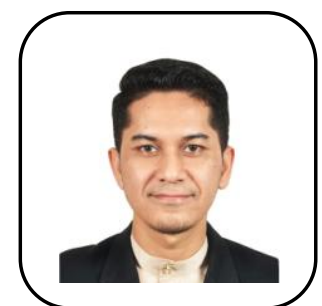

Anuaruddin Hanizan received his B. Eng. from Universiti Teknologi MARA Shah Alam in 2014 and currently pursuing his study as a master student in the Faculty of Chemical Engineering at Universiti Teknologi MARA Shah Alam. His research interest lies in polymer composite, polymer blending, dielectric materials and space charge properties of insulation materials.

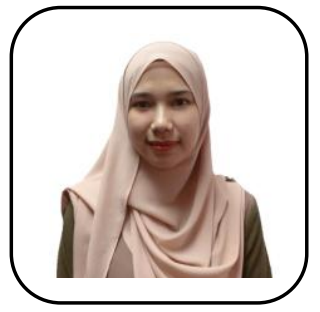

Rahida Wati Sharudin was born in Kuala Lumpur, Malaysia, in 1982. She received her Diploma in Industrial Chemistry and Bachelor Degree in Chemical Engineering in 2003 and 2006, respectively from Universiti Teknologi MARA. She was then further her study in Master and Ph.D. degrees in Chemical Engineering, major in Polymer Processing from Kyoto University, Kyoto, Japan, in 2008 and 2010, respectively. In 2006, she joined the Faculty of Chemical Engineering, Universiti Teknologi MARA as Part Time Full Time Lecturer, and after graduating her $\mathrm{PhD}$ in 2012, she became a Senior Lecturer in same University. Her current research interests include polymer foaming, polymer blending, polymer composite, polymer crystallization, optimization of foaming process via intelligence method and supercritical $\mathrm{CO}_{2}$ measurement in polymer, natural rubber and synthetic rubber. Dr. Rahida was the recipient of the Best Student Poster Presentation Awards in FOAMS 2012 International Conference, US and Japanese Society of Polymer Processing National Conference, Japan during her PhD study. She was also invited as Keynote Speaker in International Conference of the Polymer Processing, Morocco in 2011. Also in 2011, she received Best Paper of Macromolecular Journal for her outstanding study on " $\mathrm{CO}_{2^{-}}$Induced Mechanical Reinforcement of Polyolefin-Based Nanocellular Foams".

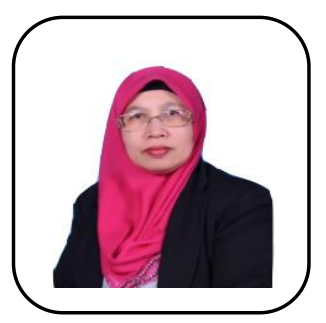

Zakiah Ahmad is a Professor in Faculty of Civil Engineering. She received the B.Sc. degree (1985) in civil engineering at Memphis State University, USA, M.Sc. degree (1995) in mathematics at University of Memphis, USA and $\mathrm{Ph} . \mathrm{D}$ degree (2008) in timber engineering at University of Bath, UK. She is now a Dean of Faculty of Civil Engineering as well as the Director of Institute for Infrastructure Engineering and Sustainable Management in Universiti Teknologi MARA, Shah Alam. Her current research is in fields of timber engineering, timber adhesive composite, wood/fibre cement composites and glued-in rod.

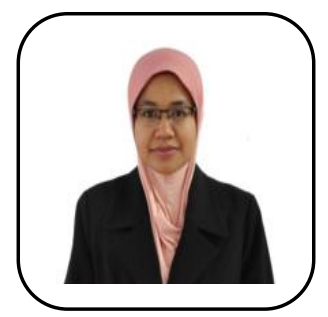

Istikamah Subuki received the Chemical Engineering degree and the $\mathrm{PhD}$ degree in Mechanical Engineering from the Universiti Teknologi MARA (UiTM) Shah Alam, Malaysia in 2004 and 2010 respectively. From 2007 to 2010, she was the researcher of the Advanced Materials Research Center (AMREC), SIRIM Berhad. She is currently a Senior Lecturer in the Faculty of Chemical Engineering, UiTM Shah Alam. Her current research interests are in advanced materials of synthesize hydroxyapatite powder, injection moulding process, develop new binder system for injection moulding process, plasma spray coating of hydroxyapatite, metal and ceramic composite and polymer composite foam.

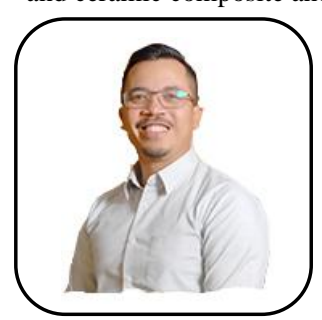

Azerai Ali Rahman obtained his Civil Engineering degree in 2005 and his master's degree in computational Mechanics of Structures and Materials in 2007 at the University of Stuttgart. He became a researcher in Structures Engineering in 2007 and since 2008 he has been of Lecturer in Civil Engineering Faculty with the Universiti Teknologi MARA (UiTM). He has carried out extensive research work in the fields of computational modeling of structures, analytical formfinding of surface tension structures, aeroelasticity (vibrations of bridges and structures), static and fatigue in railway sleepers' components and flexural performance of fiber reinforced concrete. He has authored papers presented at national and international conferences or published in specialized reviews. He is a consultant in several works for the construction industries and rail industries for several years, in general, problems of structure, such as wind induced vibration of overhead transmission line cables, the construction of Prison in Ijok, verification static test of locomotive underframe and bogie frame with SMH Rail / PROSE Switzerland, fatigue laboratory test in railway sleepers for Ipoh - Padang Besar and development of MTIB Convention Centre in Mukim Tebrau, Johor Bahru. 